\title{
0 estatuto da medicalização e as interpretações de Ivan Illich e Michel Foucault como ferramentas conceituais para 0 estudo da desmedicalização
}

Paula Gaudenzi ${ }^{1}$

Francisco Ortega ${ }^{2}$

GAUDENZI, P.; ORTEGA, F. The statute of medicalization and the interpretations of Ivan Illich and Michel Foucault as conceptual tools for studying demedicalization. Interface Comunic., Saude, Educ., v.16, n.40, p.21-34, jan./mar. 2012.

The term medicalization in the studies by Illich and Foucault was analyzed, in order to provide conceptual tools for studying movements that contest medicalization. Illich addressed hypertrophy of medicalization in modern life by emphasizing the effect of reductions of subjects' autonomy, especially through the fact that medical institutions take on the responsibility of treating pain, thus turning its intimate and personal meaning into a technical problem. Foucault approaches medicalization from the notion of biopower, and in examining the concept of governmentality, he made it possible to analyze individuals' ways of resisting the wielding of that power. Both works were concerned with proposing forms of exercising freedom, although Foucault did this in a more detailed and diversified manner. They both seem appropriate for reflecting on the current process of demedicalization or situations in which the medical diagnosis is rejected by the patient or members of his family.

Keywords: Collective health.

Medicalization. Autonomy. Biopower.
Analisa-se o termo medicalização nos estudos de Illich e Foucault, com vistas a oferecer ferramentas conceituais para o estudo dos movimentos contestatórios à medicalização. Illich aborda a hipertrofia da medicalização na modernidade, ressaltando o efeito de redução da autonomia dos sujeitos, sobretudo pelo fato de as instituições médicas assumirem a responsabilidade de cuidar da dor, transformando seu significado íntimo e pessoal em um problema técnico. Foucault aborda a medicalização a partir da noção de biopoder, e, quando trabalha a noção de governamentalidade, abre espaço para a análise das formas de resistência dos indivíduos ao exercício do poder. Ambos os trabalhos, que têm como preocupação propor formas de exercício da liberdade - apesar de Foucault o fazer de forma mais detalhada e diversificada - parecem apropriados para se pensar o processo atual de desmedicalização ou recusa do diagnóstico médico por parte de seus portadores ou familiares.

Palavras-chave: Saúde coletiva.

Medicalização. Autonomia. Biopoder.
Departamento de Ciências Humanas e Saúde, Instituto de Medicina Social, Universidade do Estado do Rio de Janeiro (IMS/ UERJ). Rua São Francisco Xavier, 524, pavilhão João Lyra Filho, $7^{\circ}$ andar, blocos D e E, Maracanã. Rio de Janeiro, RJ, Brasil. CEP 20550-900. paula. gaudenzi@gmail.com

${ }^{2}$ Departamento de Ciências Humanas e Saúde, IMS/UERJ. 


\section{Introdução}

O termo medicalização, que surgiu no final da década de 1960 para se referir à crescente apropriação dos modos de vida do homem pela medicina, é de grande relevância nos estudos críticos do campo da sociologia da saúde. Apesar de se tratar de um termo descritivo para indicar algo que "se tornou médico", a maioria dos autores o utilizou no contexto de crítica negativa ao excesso de medicalização (Conrad, 2007), através da denúncia da crescente influência da medicina em campos que até então não lhe pertenciam, criando conflitos acerca do estatuto médico, social, epistêmico ou ontológico de determinadas doenças e, portanto, da necessidade de controle e terapêutica das mesmas.

De uma forma geral, os estudos da medicalização se direcionam para a análise e insinuação da intervenção política da medicina no corpo social, por meio do estabelecimento de normas morais de conduta e prescrição e proscrição de comportamentos, o que tornaria os indivíduos dependentes dos saberes produzidos pelos agentes educativo-terapêuticos. Data do século XVIII, com o nascimento da medicina moderna e da Higiene, o início da intervenção médica na intimidade das pessoas, fazendo com que os profissionais da saúde e educadores, sobretudo, se tornassem especialistas a quem todos deveriam recorrer em busca de soluções para seus males domésticos.

Ivan Illich (1975) descreve a produção da cultura medicalizada em uma dimensão social e política, voltando seus estudos especialmente para a sociedade, em um enfoque que se poderia chamar de macrossociológico. O autor demonstra ser um crítico radical da sociedade industrial e concentra sua crítica nas tecnologias médicas ao afirmar a ameaça à saúde provocada pela medicina moderna. Uma das principais preocupações do autor é em relação à perda da autonomia das pessoas que se tornaram dependentes do saber de especialistas para o cuidado de sua saúde. Illich compreende que, para obterem uma verdadeira satisfação, as pessoas devem superar a necessidade da intervenção profissional para os cuidados em saúde e agir contra o consumo intensivo da medicina moderna.

Michel Foucault (2008a), por sua vez, apesar de não fazer uso sistemático do termo medicalização, faz referência ao processo quando aponta para a constituição de uma sociedade na qual o indivíduo e a população são entendidos e manejados por meio da medicina. Refere-se ao processo de medicalização social ao argumentar que, ao contrário do que se poderia imaginar, a medicina moderna - que nasceu no final do século XVIII, momento de desenvolvimento da economia capitalista e de esforços e expansão das relações de mercado - não se tornou individual, mas sim, se apresentou como uma prática social que transformou o corpo individual em força de trabalho com vistas a controlar a sociedade. Primeiramente, o investimento era feito sobre o indivíduo por intermédio da ação sobre o biológico e, posteriormente, controlavam-se as consciências e ideologias. Neste sentido, Foucault fala do desenvolvimento de um poder sobre a vida - um biopoder - que é exercido sobre os corpos por meio da tecnologia disciplinar (Foucault, 2006a, 2002, 1995b).

Em seus estudos do final da década de 1970, o autor aprofunda a noção de biopolítica ${ }^{3}$ para se referir às regulações exercidas sobre a população (Foucault, 2005). Uma vez que a industrialização e a força de trabalho passam a ser elementos fundamentais para a força do Estado, a análise minuciosa de cada momento da vida, das doenças endêmicas, da proporção de nascimentos, da velhice e da morte torna-se fundamental. A medicina, então, estabelece diversas medidas de controle sobre o corpo individual e coletivo, possibilitando o exercício cada vez mais refinado do poder sobre a vida.

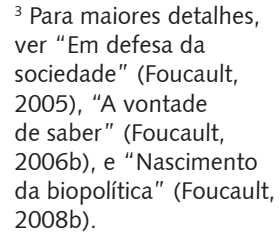

3 Para maiores detalhes, ver "Em defesa da sociedade" (Foucault, 2005), "A vontade de saber" (Foucault, 2006b), e "Nascimento da biopolítica" (Foucault, 2008b). 
Historicamente, os estudiosos da medicalização preocuparam-se em denunciar o crescente uso da racionalidade médica para abordar problemas de ordem socioeconômica-cultural, prática esta que ocasionaria a chamada culpabilização da vítima (victim blaming) (Crawford, 1977), onde o foco do problema deslocarse-ia do problema objetivo em si - suas causas e implicações - para se concentrar no aspecto subjetivo do indivíduo. Trata-se de uma ideologia que culpabiliza o indivíduo pela sua doença e propõe que, ao invés de confiar a responsabilidade das doenças aos serviços médicos caros e ineficientes ou à falta de condições dignas de vida, o indivíduo deve assumir uma maior responsabilidade por si e por sua saúde.

Apesar da importância crucial da crítica social trabalhada nestes estudos, os mesmos permanecem com o foco que, tradicionalmente, a maioria dos estudos da medicalização desenvolve: o efeito do poder sobre o indivíduo, abordando pouco - ou não abordando - o papel dos indivíduos, dos movimentos sociais e das organizações dos pacientes como atores ativos no próprio processo da medicalização.

Implicados neste contexto de crescente desenvolvimento de saberes médicos sobre o homem e sobre o social, grupos de doentes e familiares reivindicam o estatuto de doença para determinadas condições como forma de luta para a garantia de seus direitos ao tratamento, pesquisa e compensações diversas. Segundo Ortega (2009a), tal reivindicação é reflexo de uma nova forma de sociabilidade - a biossociabilidade -, em que indivíduos partilham a mesma identidade segundo critérios de saúde, se reúnem com o intuito de trocarem experiências sobre a doença que compartilham, mas também para se envolverem em um ativismo em face do desenvolvimento da biomedicina.

Pode-se dizer que esta reivindicação é possível porque as entidades nosológicas estão frequentemente sujeitas à negociação em sua existência como fato social que outorga ou retira uma determinada soma de poder aos que orbitam ao seu redor. Indivíduos que sofrem de síndrome de fadiga crônica, por exemplo, vêm se organizando para legitimar este quadro como uma categoria nosológica indisputável (Clarke, Ameron, 2007). Constituem o que Dumit (2006) tem denominado "doenças que temos que lutar para ter" (IIlnesses you have to fight to get), onde o objetivo da luta é a possibilidade de compensações que dependem da aceitação, pela comunidade, dos especialistas e de outras instâncias implicadas no processo da noção de fadiga crônica como uma síndrome física ou mental que justifique a reparação pleiteada. Esse reconhecimento geralmente envolve a procura de uma causa somática ou material da doença, pois como o historiador Charles Rosenberg $(2006$, p.414) observou: "a legitimidade social pressupõe a identidade somática".

Entretanto, na contramão da reivindicação da legitimidade do estatuto nosológico, presencia-se um movimento no campo da saúde em que a noção de estilo de vida e escolha comportamental se sobrepõe à ideia de doença ou condição patológica (Ortega, 2009a). Trata-se de um outro gênero de negociação, como, por exemplo, a do movimento da neurodiversidade, em que pessoas autistas que consideram que seu estado não é uma doença a ser tratada, mas, sim, uma especificidade humana que deve ser respeitada como qualquer outra, posicionam-se contra a busca pela cura nestes casos (Ortega, 2009b). Tal reivindicação exige a discussão dos limites entre o normal e o patológico e entre o que seria uma doença a ser tratada, por um lado, e uma diferença a ser respeitada - e até estimulada - por outro.

Outro exemplo de movimento social com vistas à desmedicalização é o

${ }^{4}$ Alguns sites de referência: www. maternidadeativa.com.br www.partodoprincipio. com.br e www. amigasdoparto.com.br. caso de mulheres no Brasil que lutam por ter partos normais em casa, livres da medicalização desnecessária do processo de parturição. Trata-se de uma luta contra o excesso de intervenção médica sobre um processo que consideram "próprio da vida". Essas mulheres se comunicam pela internet ${ }^{4}$ e propõem 
uma reforma do cuidado ao parto que produz um impacto sanitário, cultural e acadêmico significativo.

Apesar de estes movimentos, por parte dos sujeitos medicalizados, não serem expressivos quantitativamente no Brasil, pode-se dizer que o incentivo do Ministério da Saúde a políticas que se baseiam em uma visão ampliada de saúde, que valorizam a autonomia e formas de corresponsabilidade solidária - como é o caso da Estratégia de Saúde da Família (ESF) - cria a possibilidade da realização de uma atenção à saúde desmedicalizante, que permite uma maior expressão de pequenos movimentos em prol do resgate da autonomia ${ }^{5}$.

A partir do entendimento de que o processo de desmedicalização é de extrema relevância, pois se relaciona com a busca tanto da autonomia como do respeito às diferenças - condições estas fragilizadas pelo processo de medicalização -, este estudo se posiciona eticamente e se limita a apresentar uma aproximação inicial com o tema da medicalização e propor os estudos de Illich e Foucault como possíveis ferramentas para uma primeira análise dos movimentos contestatórios da medicalização, pois ambos parecem ser referências importantes para se pensar em formas possíveis de vida livre.

Apesar de o impulso de escrever este artigo ter sido o interesse pelos novos movimentos de luta contra rotulações vinculadas a entidades nosológicas, não se pretende aqui cartografar estes movimentos nem tampouco responder quais seriam as razões para a reivindicação da diferença no lugar da doença, pois isso exigiria um estudo empírico com um recorte bem definido que detalhasse as transformações nos valores e práticas sociais de grupos específicos, o que, por sua vez, exigiria conceitos e ideias muito além das desenvolvidas no fim do século XX sobre medicalização.

\section{Medicalização e as perspectivas de Ivan Illich e Michel Foucault}

O termo medicalização surge no início na década de 1960 no campo da sociologia da saúde e, doravante, se consolida como um importante campo de interesse e desenvolvimento de pesquisas. Uma vez que se observava o enorme crescimento do número de problemas da vida que eram definidos em termos médicos, os autores denunciavam a ampliação do raio de ação da medicina, que extrapolava o campo tradicional de ação direta sobre as moléstias. De fato, o crescimento da jurisdição médica foi, para alguns autores, uma das mais potentes transformações da segunda metade do século XX (Clarke et al., 2003).

Segundo Conrad (1992), o ponto-chave da medicalização é a definição quando um problema passa a ser definido em termos médicos, descrito a partir da linguagem médica, entendido através da racionalidade médica, e tratado por intervenções médicas. A partir daí formam-se categorias médicas que, de certa forma, não existiam anteriormente, tipos humanos são criados pela ciência (Hacking, 2002), mas também se modulam categorias médicas já existentes, categorias que são elásticas, no sentido de poderem ser expandidas ou retraídas.

Pode-se falar, assim, de uma medicalização por expansão diagnóstica, como é o caso da doença de Alzheimer, que, por não ser mais diferenciada da demência senil - condição "natural" do processo do envelhecimento -, se tornou uma das principais causas de morte nos Estados Unidos (Bond, 1992 apud Conrad, 2007). Com efeito, a medicalização transforma aspectos próprios da vida em patologias, diminuindo, assim, o espectro do que é considerado normal ou aceitável ${ }^{6}$.

Inicialmente, o foco dado à questão pelos sociológicos foi o da medicalização do desvio (Conrad, 1975), que incluía: o alcoolismo, as desordens mentais e alimentares, a homossexualidade, a delinquência, a disfunção sexual,

\author{
${ }^{5}$ A Promoção da Saúde \\ (PS) como conceito \\ norteador fundamental \\ da ESF pode, de fato, \\ possibilitar a valorização \\ das microculturas locais, \\ mas é importante \\ ressaltar que isso \\ depende da forma \\ como ela é entendida e \\ praticada. As propostas \\ da Educação Popular, \\ por exemplo, constituem \\ uma perspectiva libertária \\ que busca mudanças \\ sociais profundas através \\ da ênfase em mudanças \\ na relação entre o \\ cidadão e o Estado, \\ mas, por outro lado, a \\ PS pode ser utilizada de \\ forma perversa como \\ estratégia para conduzir \\ indivíduos a assumirem \\ individualmente a \\ responsabilidade por sua \\ saúde e reduzir o peso \\ financeiro na assistência \\ à saúde (Castiel, 2004).
}

\footnotetext{
${ }^{6}$ Entendemos o termo normal no sentido dado por Canguilhem (1995). que é essencialmente valorativo, uma vez que o normal como fato a ser descrito está sempre imbuído de valor por aquele que fala, em virtude de um julgamento de apreciação que o falante adota.
} 
${ }^{7}$ Foucault (1995), Freidson (1970), Zola (1972), Illich (1975)

Scheneider (1978),

Conrad e Schneider (1980) e outros. as dificuldades de aprendizagem, os abusos sexuais e infantis, entre outras categorias. A questão fundamental dos principais trabalhos sobre a medicalização era mostrar como determinados comportamentos que, até então, eram considerados imorais, passaram a ser definidos como médicos (Conrad, Schneider, 1980) - processo este trabalhado por Foucault em suas primeiras análises da noção de biopoder, em que aborda o desenvolvimento da prática política da higiene social como promessa de eliminação da delinquência e das doenças físicas e morais.

Porém, segundo autores ${ }^{7}$ da época, não apenas comportamentos desviantes, mas também processos comuns da vida, como menstruação, menopausa, envelhecimento e morte, estavam sendo cada vez mais apropriados pela medicina, tornando-se campo de saber - e poder - da mesma. Tal apropriação se traduzia na produção científica de conceitos, regras de higiene e normas de conduta pela medicina. As propostas de intervenção eram o próximo passo, e, assim, alguns autores como Freidson (1970) e Zola (1972) apresentaram as primeiras análises da medicalização e controle social ao analisarem as proposições políticas implícitas no saber produzido pela medicina e a intervenção política da mesma no corpo social. As grandes inspirações para o desenvolvimento das análises sobre medicalização e controle social foram: a teoria do rótulo (labeling theory) e o trabalho de Talcott Parsons, com sua conceitualização da medicina como uma instituição de controle social (Conrad, 1992).

Parsons (1951) - um dos pais do funcionalismo estrutural - pesquisou os significados sociais da saúde e investigou o papel da medicina não apenas como um conjunto de técnicas, mas também como um meio de controle e regulação social. O autor, de pensamento marcadamente conservador, percebia a sociedade como em equilíbrio mantido por normas e valores que estavam em constante luta contra os processos que ameaçavam seu bom funcionamento, como o crime e a doença. O objetivo de qualquer sociedade, para Parsons, era alcançar a homeostase, a manutenção do equilíbrio permanente. A doença, então, era uma forma de desvio, e a medicina, que tinha o objetivo de lutar contra as doenças, era uma instituição de manutenção do equilíbrio social.

Em sua formulação clássica do controle social, Parsons (1951) indica que o controle social exercido pela medicina se dá, sobretudo, por meio da administração e reintegração dos doentes na sociedade. Através dos conceitos de "papel social" e "papel de doente" o autor desenvolveu a ideia de que o papel social de doente evoca um conjunto de expectativas padronizadas que definem as normas e os valores apropriados ao doente e aos indivíduos que interagem com ele. Nesse esquema, a norma é sempre reforçada e o desvio é sempre punido (Parsons, 1951). A ideia que está por trás desse esquema é a de curar os doentes, sendo, a cura, sinônimo de normalidade. O desvio deve ser reprimido, os indivíduos devem ser medicalizados e normalizados.

A "teoria do rótulo", proposta por Becker (1963), considera o fenômeno do desvio de acordo com o papel da ação coletiva, cujas regras são impostas por um processo social que define coletivamente certas formas de comportamento como problemáticos. Neste sentido, Becker considera o desvio como uma transgressão àquilo que foi estabelecido como norma por um grupo e, preocupa-se, em suas análises, pelo processo através do qual os desviantes são considerados como tais pelo grupo, e suas reações a este julgamento. O interessante em seu trabalho, assim como no de Goffman (1986), é a consideração de que não há nada que defina claramente o que é uma norma nas sociedades modernas, e, neste sentido, torna-se fundamental abordar as condições nas quais as normas são instituídas. Para Becker (1963), o que é legítimo e correto para um grupo pode 
não ser necessariamente para outro e, assim, as normas só são válidas para os grupos sociais que as sustentam.

As perspectivas de Parsons - em que o desvio é entendido como um fato objetivo de não se conformar com as normas - e de Becker - em que o desviante seria caracterizado como tal como consequência de um rótulo construído socialmente e atribuído a ele por aqueles que o constroem e o tratam -, são bastante díspares, mas ambas influenciaram o desenvolvimento das análises sobre medicalização e controle social porque foram utilizadas para a reflexão sobre como a definição de normas médicas é, em si mesma, uma forma cultural de controle social que cria expectativas sobre o corpo, os comportamentos e a saúde, onde o controle se manifesta na forma em que as expectativas médicas estabelecem os limites do comportamento e do bem-estar (Conrad, 2007).

\section{Ivan Illich}

Ivan Illich (1975), no livro "Nêmesis da Medicina", lança uma forte crítica à medicina moderna e aborda o processo de medicalização a partir da noção do "imperialismo médico", termo usado pelo autor para se referir ao processo de supervisão médica de todos os aspectos - ordinários - da vida. O autor considera que a medicalização da vida foi resultado da industrialização, que trouxe consigo a profissionalização e burocratização da instituição médica. Para Illich, que conservava o discurso ácido sobre o poder médico, a medicina institucionalizada representava, na realidade, uma ameaça à saúde. Neste sentido, o autor faz uso da noção de iatrogênese - iatros (médico) e genesis (origem) - para falar da nova epidemia de doenças provocadas pela medicina. A partir da noção de contraprodutividade, descreve este processo em que o sistema médico, criado para proteger a saúde, estava, paradoxalmente, acabando com a mesma e produzindo doença.

Illich aborda a iatrogênese em três níveis que, em conjunto, contribuem para aquilo que considera o grande mal da medicina: o comprometimento da capacidade autônoma dos homens. O primeiro deles é a iatrogênese clínica, que se refere às doenças causadas pelos próprios cuidados de saúde, como: os efeitos secundários não desejados dos medicamentos, intervenções cirúrgicas inúteis, produção de traumatismos psicológicos, negligência, incompetência e outros. Neste sentido, apesar de o autor reconhecer o bem que a medicina pode produzir, faz uma dura crítica à ingestão excessiva de medicamentos, que causaria mais mal do que bem, provocando novas espécies de doenças que não podem ser curadas pela técnica moderna, pela imunidade natural, nem pela cultura tradicional ${ }^{8}$.

O segundo nível, de grande relevância para os fins deste artigo, é o da iatrogênese social, que pode ser entendido como sinônimo de medicalização social. Trata-se do efeito social não desejado e danoso do impacto social da medicina, mais do que o de sua ação técnica, como é o caso da iatrogênese clínica. Neste sentido, a iatrogênese social corresponde à crescente dependência da população para com as prescrições da medicina. O sentido de saúde enquanto responsabilidade de cada indivíduo dá lugar à ideia de "papel do doente" (Parsons, 1951), que é aquele de sujeito passivo e dependente da autoridade médica. É sobretudo a produção de dependência, mais do que de lesões orgânicas ou distúrbios funcionais, que, segundo Illich, caracteriza o maior dano provocado pela proliferação dos profissionais de saúde e da ideologia médica.

Illich (1975) indica diversas formas de iatrogênese social. A primeira delas é a medicalização do orçamento, em que se observa que o nível de saúde não
${ }^{8}$ Nota-se o acerto de Illich expresso na pesquisa de Starfield (2000) que apresenta o total de 225.000 óbitos por ano devido a causas iatrogênicas nos Estados Unidos da América, tornando a iatrogenia uma das principais causas de óbito nesse país. 
melhora apesar dos aumentos das despesas médicas. Tal percepção de que a empresa médica era ineficaz para dar conta da saúde da população foi um dos motores do desenvolvimento da Promoção da Saúde. Apesar do termo "promoção da saúde" ter surgido no início do século XX, com Sigerist (1946), o campo se desenvolveu na década de 1970, a partir do Relatório Lalonde de 1974 (Lalonde, 1981), cujo objetivo central era a redução dos custos da assistência medica. Para Illich (1975), a medicalização do orçamento reflete a ilusão de que o grau de cuidados no campo da saúde é representado pelas curvas de distribuição dos produtos da instituição médico-farmacêutica.

A segunda forma de iatrogênese social seria a invasão farmacêutica, termo descrito por Dupuy e Karsenty (1974) em referência às despesas farmacêuticas que aumentariam a uma taxa vertiginosa, ainda maior que a taxa referente às despesas médicas. Ao abordar esta forma de iatrogênese, Illich deixa transparecer seu tom amargo, radical e pessimista em relação aos profissionais médicos, colocando-os na condição de atores ativos de um processo de subsunção dos doentes ao superconsumo de medicamentos. Segundo Illich (1975, p.52), "O médico pesquisa a eficácia do ato técnico ainda que à custa da saúde do doente e este submete seu organismo à regulagem heterônima, o que quer dizer que ele se transforma em paciente".

Outra forma de iatrogênese social seria o controle social pelo diagnóstico, resultante da medicalização das categorias sociais. Neste sentido, o autor se refere à etiquetagem iatrogênica das diferentes idades da vida humana, onde as pessoas passam a aceitar como "natural" a necessidade de cuidados médicos de rotina pelo fato ordinário de serem gestantes, recém-nascidas, crianças ou velhas. Para o autor, neste momento, a vida deixa de ser uma sucessão de diferentes formas de saúde e de ser e estar no mundo, e se torna "uma sequência de períodos cada qual exigindo uma forma particular de consumo terapêutico" (Illich, 1975, p.56).

Por fim, Illich (1975) aborda o nível da iatrogênese estrutural ou cultural, em que a medicina moderna retira do sofrimento seu significado íntimo e pessoal e transforma a dor em problema técnico. Desta forma, a perda advém da destruição do potencial cultural das pessoas para lidarem de forma autônoma com a enfermidade, com a dor e com a morte, causando o que Illich chama de regressão estrutural do nível de saúde. O autor está chamando atenção para as regras criadas pela Higiene, que estariam substituindo a ação autônoma individual para lidar com a precariedade da vida pela obediência às instruções que emanam de profissionais terapeutas que ditam formas corretas de comer, dormir, amar, divertir-se, sofrer e morrer (Illich, 1975).

De fato, Illich (1975) faz uma abordagem radical e inovadora sobre a medicina moderna, afirmando que o estabelecimento médico no ocidente representa uma ameaça à saúde, pois retira dos indivíduos a capacidade de lidarem com os processos de vida, incluindo o sofrimento. O processo da medicalização retira-Ihes sua condição autônoma e os coloca como sujeitos passivos de cuidados heterônomos. Neste processo, a medicina moderna se apresenta propositalmente complicada com o intuito de esconder a simplicidade dos atos e se tornar a grande detentora do saber sobre os processos da vida e sobre o sofrimento, criando, assim, uma dependência progressiva do paciente em relação ao médico. Desta forma, diferentemente da compreensão de Canguilhem (1995) sobre a saúde a capacidade de lidar com os obstáculos da vida recriando novas formas de estar no mundo -, a medicina, segundo Illich, agiria em um movimento contrário, pois retiraria dos indivíduos a capacidade de pensarem e atuarem sobre si; cuidarem de si.

Neste nível de análise, assim como no da iatrogenia social, Illich indica a produção de uma cultura medicalizada e, apesar de seu linguajar fortemente crítico e amargo, deixa transparecer a proposta de resgate ou reinvenção da autonomia das pessoas no processo de cuidado da própria saúde, o que poderia se dar através da luta política pelo direito à intensidade do ato produtivo pessoal. Ivan Illich, a quem Nogueira (2003) atribui o cognome de profeta da autonomia, concebe a possibilidade de uma via de resgate para o instrumentalismo industrial moderno, reequilibrando a sinergia das ações heterônomas e autônomas no cuidado da saúde.

Apesar de Illich enfatizar o lado opressivo da cultura medicalizada ocidental, seu estudo - uma vez que se destina a oferecer instrumentos para se pensar no restabelecimento de um equilíbrio éticopolítico entre ações de saúde autônomas e heterônomas - permite analisar a crescente aparição de movimentos contestatórios à medicalização, aquilo que Foucault, de forma mais explícita e detalhada, 
apresentou através de sua visão de poder e governamentalidade, em que a possibilidade de invenção de formas de resistência a partir das lutas em torno da subjetividade era uma realidade sempre presente.

Segundo Illich, apenas com uma desmedicalização que limitasse a intensidade das terapias heterônomas, o indivíduo poderia resgatar sua autonomia. Para ele, a desmedicalização passa pelas dimensões do direito e da liberdade de ordenamento público da saúde. Assim, admite que o direito à saúde como liberdade tem um horizonte mais amplo e precede ao direito ao acesso aos serviços heterônomos, afirmando que é exatamente o reconhecimento dessa precedência o fundamental para que a produção de serviços de saúde seja mantida em níveis que não gerem iatrogênese (Nogueira, 2003).

Illich não restringiu seus estudos à análise das formas de danos à saúde provocados pela perda da capacidade de ação autônoma dos indivíduos e às formas possíveis de liberdade em uma sociedade marcada pela institucionalização da medicina. Nos anos 1980, o autor refere-se à iatrogênese do corpo, onde o maior agente patogênico seria a busca do corpo sadio (Illich, 1992) devido à busca patogênica da saúde. Para Illich, na contemporaneidade, a saúde materializada no corpo transformou-se num objeto de busca obsessiva para realização pessoal e, também neste ponto, Illich se aproxima de Foucault (2008b, 2006b) no estudo da história do corpo e das práticas relacionadas a ele. Neste momento percebe-se uma mudança de abordagem de Illich, que desloca o foco dos médicos para as grandes indústrias, os meios de comunicação e outros agentes terapêuticos.

Antes de iniciar a apresentação do que seria a perspectiva foucaultiana da medicalização, é importante deixar claro que Foucault não se opõe ao estudo de Illich. Ambos os autores foram importantes críticos do "modelo biomédico", o qual afirmava que as patologias individuais e coletivas poderiam ser diagnosticadas e curadas de acordo com uma concepção orgânica de saúde e doença. Para Illich, assim como para Foucault, os desviantes não eram vilões, mas, sim, vítimas de rotulagem e discriminação, invertendo completamente a posição ortodoxa da época. Eram os médicos, psiquiatras e cientistas que, através de seus conhecimentos e autoridade (saber-poder), fortaleciam a ordem dominante, segregando e patologizando o desobediente (Nye, 2003).

O que parece mais claramente diferenciá-los é a ênfase que cada um oferece ao papel do indivíduo diante do exercício deste poder. Enquanto Illich parece ter priorizado a análise do significado cultural e social mais macrossocial ${ }^{9}$ das transformações operadas pela medicalização na cultura, deixando transparecer menos a produção de subjetividades como aspecto positivo do poder da medicalização, Foucault aborda as formas de resistência - sempre presentes - dos indivíduos ao exercício do poder como tema seminal de sua análise do poder. São, sobretudo, a positividade, a eficácia produtiva do poder, a criação de novas formas de vida livres, que interessam a Foucault em seu estudo sobre o poder. Neste sentido, Foucault aborda o processo de medicalização em uma perspectiva distinta mas não intencionalmente diferente daquela de Illich, e o analisa como característica central da sociedade moderna, no seio de sua elaboração da noção de biopoder.

\section{Michel Foucault}

Ao falar de biopoder, inicialmente, Foucault está falando de um poder que historicamente sucedeu ao modelo da soberania, a qual estava inoperante para reger o corpo econômico e político de uma sociedade em via de explosão
${ }^{9}$ Nogueira chama atenção para o fato de Illich também desenvolver uma microeconomia do poder ao defender a tese de que "as forças produtivas, mesmo que continuem a se desenvolver na dimensão técnico-científica, impulsionadas pela sociedade, deixam de funcionar a contento localmente e tornamse destrutivas, se esse reequilíbrio sinérgico entre heteronomia e autonomia não vier a acontecer" (Nogueira, 2003, p.29). 
demográfica e de industrialização. Este descarte culmina com a rejeição da noção negativa e repressora do poder e, então, Foucault (2005) fala de uma mecânica de poder que, a partir dos séculos XVII e XVIII, se direciona para a gestão e maximização da vida. Neste momento de tematização do biopoder - estudos realizados na primeira metade da década de 1970 - a noção jurídica e repressora de poder é rejeitada, a forma central do exercício do poder é a disciplina, e os principais temas trabalhados são: a medicalização e a normalização da sociedade moderna, a constituição e afirmação da família burguesa sexualizada, e a consolidação do Estado-Nação.

Foucault estuda o poder rompendo com as noções clássicas do termo. Para o autor, o poder não pode ser entendido como algo que o indivíduo simplesmente cede ao soberano, mas deve ser compreendido como relação de forças em uma determinada sociedade, em um vínculo prático que une o poder e o objeto do poder. Não haveria, assim, os detentores do poder de um lado e os que se encontram alijados dele do outro, pois o poder entendido desta forma, a rigor, não existe; o que existe são práticas ou relações de poder. O poder, para Foucault, não pode ser localizado em uma única instituição, ou no Estado, pois é determinado por um jogo de saberes que respaldam o fazer da dominação de uns indivíduos sobre outros e, sendo uma relação, está necessariamente em todas as partes (Machado, 2009).

Em relação às lutas contra o exercício do poder, considerando o caráter relacional do poder, o fato de estar em todos os lugares, abarcando tudo e todos, e o fato de haver sempre resistência onde há poder, Foucault afirma que não existe propriamente o lugar da resistência, mas pontos móveis e transitórios que se distribuem por toda a estrutura social. A tese de Foucault é a de que o poder possui uma eficácia produtiva, e "é justamente este aspecto [a positividade do poder] que explica o fato de ele ter como alvo o corpo humano, não para supliciá-lo, mutilá-lo, mas para aprimorá-lo, adestrá-lo" (Machado, 2009, p.172). Foucault refere-se a uma mecânica de poder plural e inventiva, poder este que é criado e expandido pela medicina moderna.

Para Foucault (2008a, 2002), a medicina passa, no século XVIII, a exercer um papel fundamental no controle e gestão do corpo, interferindo nos modos de vida e nas condutas individuais e coletivas através da definição de regras que deveriam orientar a vida moderna, não apenas no que diz respeito à doença, mas também às formas gerais do comportamento humano, como a sexualidade, a fecundidade, a fertilidade e outros. Doravante, o vocabulário e a racionalidade médicos passam a ser utilizados como forma de poder do governo sobre a população, o qual passa a analisar, em termos médicos, comportamentos desviantes como: a delinquência, a criminalidade e o alcoolismo.

Porém, nos primeiros estudos de Foucault sobre o biopoder, a ênfase é dada sobre a constituição da medicina clínica e sua função fundamental na sujeição e direção dos indivíduos, deixando de abordar as formas de resistência possíveis dos indivíduos. Pode-se dizer que Foucault (2006a, 2002, 1998, 1995b), no início dos anos 1970, dirigiu seus estudos para o papel do médico na modernidade de ensinar as normas de boa higiene, interferindo nos modos de vida ao criar regras que deveriam orientar a vida moderna. Dessa forma,

10 Segundo Lupton (1997), Foucault não fez um uso típico do termo medicalização, ao contrário, apresentou o impacto do discurso médico na vida das pessoas. Foucault já identificara o movimento da medicalização no século XVIII, mas tal movimento estava intimamente relacionado com a noção de biopoder que desenvolvera, não abordando profundamente a questão a partir do termo medicalização ${ }^{10}$.

Em meados da década de 1970, Foucault (2008b) desenvolve a noção de biopolítica para afirmar que, desde o século XVIII, a medicina exerce um papel 
de controle e gestão do corpo que não é apenas individual. O controle se faz também sobre o "corpo social". A sociedade passa então a ser pensada e organizada em termos estritamente médicos. Neste sentido, poder-se-ia falar de uma medicalização do social, em que a gestão da saúde da população ganhava uma importância cada vez maior e o exercício do poder sobre a vida passava a englobar, também, a regulação das cidades, através da higiene pública, exemplificada na constituição da medicina urbana francesa. Para Foucault, a medicina passa a oferecer a matéria-prima das regras que devem orientar a vida moderna nas formas gerais de existência e do comportamento humano, sendo a instância criadora de normas de saúde e de vida, orientando comportamentos e definindo o que está dentro e o que está fora da norma.

Nos estudos do final da década de 1970, o autor traz a noção de governo para pensar no tipo de poder que recai sobre um cidadão autônomo que abraça seus deveres sociais. Como afirma Nye (2003), a noção de governamentalidade de Foucault permite reconhecer a ação do sujeito sem recorrer à noção de plena autonomia ou a explicações de comportamentos voluntários. Neste momento, Foucault busca analisar a introdução das noções de governo e governamentalidade, de poder pastoral e da temática do liberalismo, em suas relações com o biopoder.

Neste sentido, o poder deixa de ser considerado apenas como uma ação exercida sobre um corpo para adestrá-lo e torná-lo dócil, e a liberdade passa a ser vista como condição essencial para o exercício do poder, abrindo espaço para a criação de novas ações resistentes, isto é, para a luta contra as formas de dominação étnica, social ou religiosa; contra as formas de exploração que separam os indivíduos do que eles produzem; e contra as formas de sujeição que vinculam o sujeito consigo mesmo (Castro, 2009). De fato, é apenas com o conceito de "governamentalidade" que Foucault "salva" a medicalização, ao centrar seus estudos na noção de governo de si, em que analisa as formas pelas quais os indivíduos se constituem como sujeitos morais.

Em um texto de 1982, intitulado "O sujeito e o poder", Foucault (1995a) deixa claro que seu interesse pelo poder advém do entendimento de que o sujeito moderno, em sua constituição, encontra-se intrincado em complexas lutas de poder em torno da subjetividade. O autor está preocupado com a liberdade de invenção da ação humana, que seria condição para o exercício do poder. As lutas em torno da subjetividade são pensadas pelo autor como momentos de criação de novas subjetividades, de novas ações, havendo sempre a possibilidade de criação e invenção de resistências necessariamente ativas no mundo, que criam outras possibilidades de exercício políticoético da liberdade.

Foucault rejeita a noção de que os indivíduos seriam passivos ou acríticos diante da expansão da medicina; e, ao contrário, acreditando na possibilidade de diferentes formas de ser e estar no mundo e na criação constante de novas formas de vida, Foucault pretendeu analisar as formas pelas quais os indivíduos se constituem como sujeitos morais, preocupando-se com os modos de subjetivação em que o sujeito se constitui a partir de práticas que permitem, ao indivíduo, estabelecer uma determinada relação consigo mesmo e com os outros (Ortega, 1999). Interessou-se, assim, pelo que chamou de "artes da existência", isto é, as práticas racionais e voluntárias pelas quais os homens não apenas determinam para si mesmos regras de conduta - sendo, portanto, práticas de liberdade - como, também, buscam transformar-se, modificar-se em seu singular, e fazer de sua vida uma obra que seja portadora de certos valores estéticos, uma obra de arte (Foucault, 2006c).

\section{A recusa do diagnóstico médico - considerações finais}

As motivações que levam à desmedicalização ou recusa do diagnóstico por parte de seus portadores são muitas e complexas. Uma questão crucial implicada nesta reflexão é a de que a "saúde" - e, portanto, também a "doença" - é culturalmente configurada e socialmente sustentada, isto é, possui diversos significados culturais, e diferentes ideologias estão envolvidas em sua definição. Se por um lado a saúde é um estado desejado, por outro, é também um estado prescrito e uma posição ideológica (Metzl, Kirkland, 2010). Desta forma, há sempre uma abertura para a discussão do diagnóstico imputado através de argumentos de base científica, cultural e/ou ideológica, cujo predomínio da base argumentativa depende do tipo de doença que está em questão. 
Neste panorama vê-se a expansão do campo dos disabilty studies, que coloca em questão a legitimidade do modelo médico de compreensão da deficiência que a entende como uma experiência privada, caracterizada como uma catástrofe pessoal, levando à estigmatização e vergonha por parte de seus portadores. Trata-se de um campo que - como qualquer outro - é composto de posições diversas e, às vezes, opostas, sendo marcado, sobretudo, pelo modelo da Tragédia Pessoal e pelo Modelo Social da Deficiência. Se o primeiro estabelece uma relação causal entre lesão e deficiência, e faz desta última objeto de controle biomédico, o segundo compreende a deficiência como uma experiência de opressão social, sendo definida não pela lesão, mas sim pelo ordenamento tipicamente capitalista que pressupõe um tipo ideal de sujeito produtivo (Oliver, 1990).

Neste contexto vê-se, por um lado, a resistência ao diagnóstico como é dado pela medicina e, por outro, a valorização de singularidades anatomofisiológicas, consideradas tradicionalmente como desvios de regras de normalidade, tratando-se de um movimento que pode representar uma recuperação da dignidade ética para estes indivíduos a partir da revalorização das singularidades físicas (Ortega, 2008).

Estas questões, amiúde, escapam aos principais debates acerca da medicalização, cuja perspectiva tende a ofuscar as experiências subjetivas do "ser medicalizado", que podem adquirir diversos significados psicológicos, existenciais, morais, políticos e sociais. A reivindicação ou o repúdio do diagnóstico, na contemporaneidade, não tem um sentido único. A depender das circunstâncias históricas, configuram formas de pensar sobre si e sobre a relação com os outros, irredutíveis a uma única forma de vida.

Neste artigo, importou-nos uma primeira aproximação com a ideia de que a recusa do diagnóstico da deficiência representa um processo de desmedicalização, no sentido foucaultiano do termo: um ato de resistência, inerente ao indivíduo e a qualquer relação de poder, resistência esta que é a mola propulsora da subjetividade. A partir dessa noção, mostramos que as abordagens de Illich e Foucault, em sua primeira análise do biopoder, dão ênfase à dimensão social e política mais geral da medicalização, enquanto Foucault, em sua análise posterior, enfatiza a dimensão mais intimista e microssocial das possibilidades de resistência contra a medicalização.

Nosso interesse neste artigo não foi compreender os motivos e as consequências do surgimento das novas formas de vida a partir das práticas médicas, mas sim apresentar uma introdução ao tema da medicalização e dos movimentos desmedicalizantes visando afirmar os trabalhos de Ivan Illich e Michel Foucault como referências importantes para se pensar nas possibilidades de liberdade e autoprodução mais autônoma da vida.

\section{Colaboradores}

Os autores trabalharam juntos em todas as etapas de produção do manuscrito.

\section{Referências}

BECKER, H. Outsiders. New York: Free Press, 1963.

BOND, J. The medicalization of dementia. J. Aging Stud., v.6, n.4, p.397-403, 1992.

CANGUILHEM, G. O normal e o patológico. Rio de Janeiro: Forense Universitária, 1995.

CASTIEL, L.D. Promoção de saúde e a sensibilidade epistemológica da categoria

"comunidade". Rev. Saude Publica, v.38, n.5, p.615-22, 2004.

CASTRO, E. Vocabulário de Foucault: um percurso pelos seus temas, conceitos e autores. Belo Horizonte: Autêntica, 2009. 
CLARKE, A. et al. Biomedicalization: technoscience, health, and illness in the U.S biomedicine. London: Duke University Press, 2003.

CLARKE, J.; VAN AMEROM, G. Surplus suffering: differences between organizational understandings of Asperger's syndrome and those people who claim the 'disorder'. Disability Soc., v.22, n.7, p.761-76, 2007.

CONRAD, P. The medicalization of society: on the transformation of human conditions into treatable disorders. Baltimore: The Johns Hopkins University Press, 2007. 1992.

Medicalization and social control. Annu. Rev. Sociol., v.18, (August), p.209-32,

. The discovery of hyperkinesis: notes on the medicalization of deviant behavior Soc. Prob., v.23, n.1, p.12-21, 1975.

CONRAD, P.; SCHNEIDER, J.W. Deviance and medicalization: from badness to sickness. Philadelphia: Temple University Press, 1980.

CRAWFORD, R. You are dangerous to your health: the ideology and politics of victim blaming. Int. J. Health Serv., v.7, n.4, p.663-80, 1977.

DUMIT, J. Illnesses you have to fight to get: Facts as forces in uncertain, emergent illnesses. Soc. Sci. Med., v.62, n.3, p.577-90, 2006.

DUPUY, J.P.; KARSENTY, S. L`invasion pharmaceutique. Paris: Seuil, 1974.

DREYFUS, H.L.; RABINOW, P. Michel Foucault: uma trajetória filosófica - para além do estruturalismo e da hermenêutica. Rio de Janeiro: Forense Universitária, 1995a. p.231-49.

FOUCAULT, M. Microfísica do poder. São Paulo: Edições Graal, 2008a.

Nascimento da biopolítica. São Paulo: Martins Fontes, 2008b.

O poder psiquiátrico: curso no Collège de France (1973-1974). São Paulo:

Martins Fontes, 2006a. $2006 b$.

História da sexualidade I: a vontade de saber. Rio de Janeiro: Edições Graal,

Ética, sexualidade e política, ditos e escritos V. Rio de Janeiro: Forense Universitária, 2006c.

Em defesa da sociedade: curso no Collège de France (1975-1976). São Paulo: Martins Fontes, 2005. Fontes, 2002.

Os anormais: curso no Collège de France (1974-1975). São Paulo: Martins

O nascimento da clínica. Rio de Janeiro: Forense Universitária, 1998.

. Vigiar e punir: nascimento da prisão. Petrópolis: Vozes, 1995b.

O sujeito e o poder. In: DREYFUS, H.; RABINOW, P. (Orgs.).

FREIDSON, E. Profession of medicine: a study of the sociology of applied knowledge. Chicago: University of Chicago Press Edition, 1970.

GOFFMAN, E. Stigma. New York: Simon/Schuster, 1986.

HACKING, I. Historical ontology. Cambridge: Harvard University Press, 2002.

ILLICH, I. In the mirror of the past, lectures and adresses, 1978-1990. New York: Marion Boyars, 1992.

1975.

A expropriação da saúde: nêmesis da Medicina. Rio de Janeiro: Nova Fronteira, 
LALONDE, M. A new perceptive on the health of Canadians: a working document. Ottawa: Ministry of Health and Welfare, 1981.

LUPTON, D. Foucault and the medicalisation critique. In: PETERSON, A.; BUTON, R. (Orgs.). Foucault, health and medicine. London: Routledge, 1997. p. 94-110.

MACHADO, R. Foucault, a ciência e o saber. Rio de Janeiro: Jorge Zahar, 2009.

METZL, J.M.; KIRKLAND, A. Against health: how health became the new morality. New York: New York University Press, 2010.

NOGUEIRA, R.P. A saúde pelo avesso. Natal: Seminare, 2003.

NYE, R. The evolution of the concept of medicalization in the late twentieth century. J. Hist. Behav. Sci., v.39, n.2, p.115-29, 2003.

OLIVER, M. The politics of disablement. New York: Palgrave Macmillan, 1990.

ORTEGA, F. Deficiência, autismo e neurodiversidade. Cienc. Saude Colet., v.14, n.1, p.67-77, 2009a.

The cerebral subject and the challenge of neurodiversity. BioSocieties, v.4, n.4, p.425-45, 2009b.

O corpo incerto: corporeidade, tecnologias medicas e cultura contemporânea. Rio de janeiro: Garamond, 2008.

Amizade e estética da existência em Foucault. Rio de Janeiro: Graal, 1999.

PARSONS, T. The social system. New York: Free Press, 1951.

ROSENBERG, C.E. Contested boundaries: psychiatry, disease, and diagnosis. Perspect. Biol. Med., v.49, n.3, p.407-24, 2006.

SCHNEIDER, J.W. Deviant drinking as disease: alcoholism as a social accomplishment. Soc. Probl. v.25, n.4, p361-72, 1978

SIGERIST, H.E. The university at the crossroads. New York: Henry Schumann Publishers, 1946.

STARFIELD, B. Is US health really the best in the world? JAMA, v.284, n.4, p.483-5, 2000.

ZOLA, I. Medicine as an institution of social control. Sociol. Rev., v.4, p.487-504, 1972. 
GAUDENZI, P.; ORTEGA, F. El estatuto de la medicación y las interpretaciones de Ivan Illich y Michel Foucault como herramientas conceptuales para el estudio de la des-medicalización. Interface - Comunic., Saude, Educ., v.16, n.40, p.21-34, jan./mar. 2012.

Este articulo analiza el término medicación en los estudios de Illich y Foucault con el objetivo de ofrecer herramientas conceptuales para el estudio de los movimientos resistentes a la medicación. Illich aborda la hipertrofia de la medicación en la modernidad subrayando el efecto de reducción de la autonomía de los sujetos, ya que las instituciones médicas asumen la responsabilidad de cuidar del dolor, transformando su significado íntimo y personal en un problema técnico. Foucault trata la medicación a partir de la noción de bio-poder. Al analizar la noción de guber-mentalidad abre espacio para el análisis de formas de resistencia de los individuos al ejercicio del poder. Ambos trabajos se preocupan en proponer formas de ejercicio de la libertad y parecen apropiados para entender el proceso actual de des-medicación o de rechazo al diagnóstico medico por parte de sus portadores o familiares.

Palabras clave: Salud Colectiva. Medicación. Autonomía. Biopoder. 